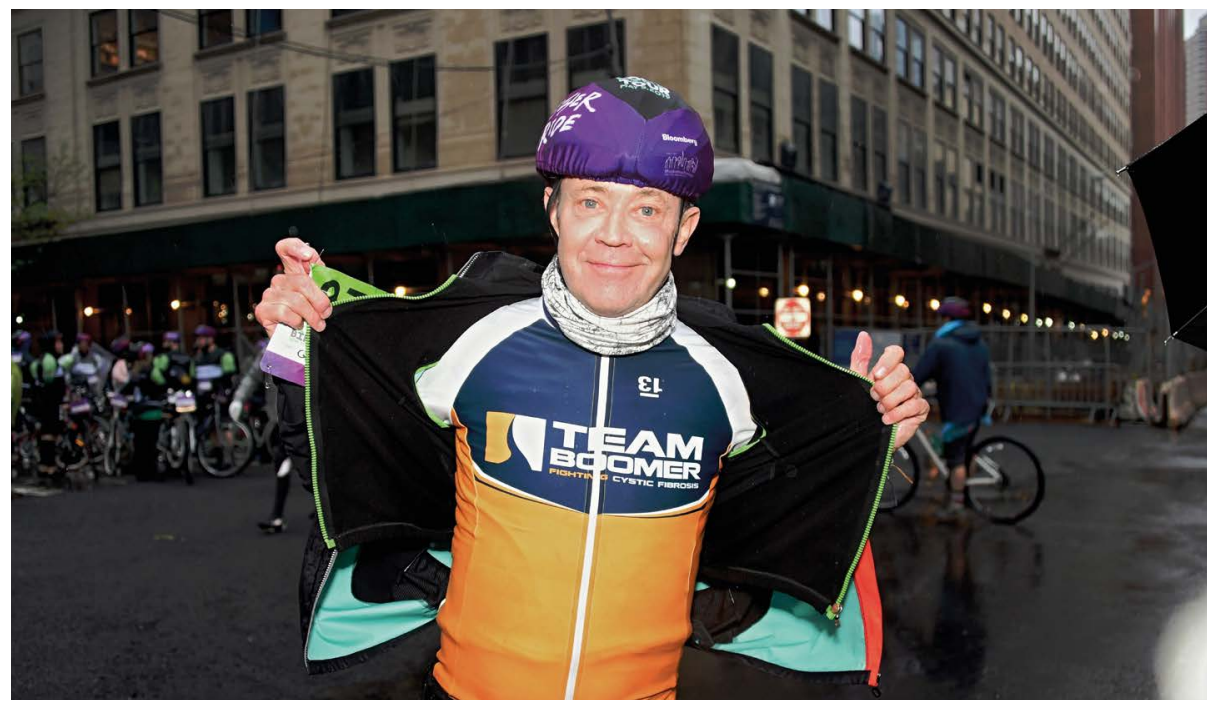

Jerry Cahill was diagnosed with cystic fibrosis at the age of 10 . He is now 64.

\title{
Living, breathing proof
}

\section{Some people have defied the short life expectancy associated with cystic fibrosis. By Roxanne Khamsi}

N an Graham was in the waiting room of her obstetrician's office in 1964 when she came across a magazine article that shook her to the core. It described the symptoms of cystic fibrosis, and she immediately thought of her two-year-old son Howell, who had been suffering from diarrhoea since he was born. Graham tore out the page and dashed from the offices before her appointment. She told her husband, a major in the US Navy, to put on all his medals and accompany her back to the hospital, where she persuaded sceptical doctors - who insisted her toddler was healthy - to test the child for cystic fibrosis.

When the result came back positive, the physicians who had been dismissive were suddenly sombre. One said that her son would not make it to the age of six. "He said, 'I hope you have a good camera. Take lots of pictures of this child. He will never see first grade,'” she recalls.

Today, at age 58, Howell Graham is still very much alive. He works as a real-estate appraiser and has been married to his wife for nearly 30 years. Graham is one of a group of individuals with cystic fibrosis who have defied the predictions of doctors and survived for decades with the disease. The illness causes progressive damage to organs such as the lungs, usually leading to premature death as a result of respiratory failure. However, the life expectancy for people with cystic fibrosis has risen in past decades, particularly in nations with good access to care. An analysis of countries in Europe, Australasia and North America found that the median life expectancy went up from 8 years in 1974 to 21 years in 1994 (A. Fogarty, R. Hubbard and J. Britton Chest 117, 1656-1660; 2000). Another study found the death rate from the disease in the United Kingdom decreased by $2 \%$ annually from 2006 to 2015 (R. H. Keogh et al.J. Cyst. Fibros. 17, 218-227; 2018). In the United States, the life expectancy for people with cystic fibrosis is now around 44 years, according to the non-profit organization the Cystic Fibrosis Foundation.

\section{Life extension}

The improvement is due in part to better antibiotics, which can help to stave off potentially fatal lung infections. Better nutritional support, such as enzyme pills that aid the digestion of fatty foods, has also helped to stop clogging in the ducts that deliver digestive enzymes. Moreover, newborn screening programmes have allowed affected people to be identified and get care earlier than before.

However, the life expectancy for people with cystic fibrosis is not equal everywhere. In Canada, where there is broad public health insurance and it is possible to get on a waiting list for a lung transplant before becoming severely ill, people with cystic fibrosis tend to live ten years longer than their counterparts in the United States, who do not have these advantages. And in poorer countries, the life expectancy is much shorter - in some places, as low as ten years of age.

Many people with cystic fibrosis who are over 50 have lung transplants to thank for their survival. Howell Graham underwent the procedure in 1990. According to Thomas Egan - the surgeon who performed the transplant and who is now a professor at the University of North Carolina at Chapel Hill - Graham is the longest-living person in the world who has undergone a bilateral lung transplant. Egan stresses that lung transplants require patients to be on long-term immunosuppressants, which can place them at risk of infection, and that the steroids that patients take after the procedure can alter glucose metabolism, putting them at risk of diabetes. "The thing about transplants is that, all of a sudden, these previously chronically ill people feel great," he says. "And they eat, and steroids unfortunately really rev up your appetite. So a lot of people after organ transplant gain weight."

Jerry Cahill is 64 years old and is living with diabetes that developed after he received a lung transplant for his cystic fibrosis. But he says he also has to keep close tabs on his liver because of all the drugs he has had to take to manage his disease over the years. Liver disease is a concern in cystic fibrosis because clogged ducts can cause bile to accumulate in that organ, which might lead to inflammation.

Fertility issues can also be a worry for people with cystic fibrosis. The disease can cause blockages in the vas deferens that deliver sperm out of the testes. And women who undergo lung transplants are often advised against pregnancy because it is thought to increase the risk of organ rejection.

Cahill, who was ten years old when he was diagnosed, says that the children with cystic fibrosis he meets are incredulous when he tells them he has the same disease. "They're like 'Wow - I didn't know anyone with cystic fibrosis could live that long,"' he says.

Howell Graham has had similar experiences. "People find me on the Internet," he says. He tries to give them encouragement. "It's a tough disease, and people want to give up. Don't give up," he tells them.

Cahill likewise tries to tell people it is possible to persevere. "I keep beating the odds," he says. "I've outlived some of my doctors."

Roxanne Khamsi is a science journalist based in Montreal, Canada. 